\title{
Sudden death in an adolescent due to primary angiosarcoma of the right atrium
}

Corresponding author:

Co-Authors:
Lorraine du Toit-Prinsloo

Egbert C.A. van Niekerk

Christien M. Cronjé

Jurgen Dinkel

Affiliation, degrees and addresses of the authors: (affiliation underlined, degrees in italic)

ECA van Niekerk: $\quad$ Medical officer; University of Pretoria; Department of Forensic Medicine, Private Bag X323, ARCADIA, 0007 SOUTH AFRICA

MBChB, MMed(Anaes), DipForMed(SA)Path

CM Cronjé: $\quad$ Specialist; University of Pretoria \& National Health Laboratory Service, Tshwane Academic Division; Faculty of Health Sciences, Department of Anatomical Pathology, Private Bag X323, ARCADIA, 0007 SOUTH AFRICA MBChB, DipForMed(SA)Path, MMed(Path)(Forens), MMed(Anat)(Path)

J Dinkel: $\quad$ Specialist; $\quad$ University of Pretoria \& National Health Laboratory Service, Tshwane Academic Division; Faculty of Health Sciences, Department of Anatomical Pathology, Private Bag X323, ARCADIA, 0007 SOUTH AFRICA MBChB, MMed(Anat)(Path)

L du Toit-Prinsloo: $\quad$ Specialist / Lecturer; University of Pretoria; Department of Forensic Medicine, Private Bag X323, ARCADIA, 0007 SOUTH AFRICA MBChB, Dip For Med(SA)Path, FCForPath(SA), MMed(Path)(Forens)

E-mail address, telephone and fax numbers of the corresponding author:

L du Toit-Prinsloo

Email: $\quad$ lorraine.dutoit@up.ac.za

Telephone numbers: $\quad+27(0) 123235298$ (work)

+27 (0)83406 4056 (mobile)

Fax number: $\quad$ +27(0)123230921

\section{Keywords:}

Angiosarcoma

Cardiac tumours

Cardiomegaly

Post mortem examination

Sudden cardiac death 


\section{Case presentation}

A 16 year old male adolescent of African ethnicity, presented to a health care facility with a long standing history of chronic coughing. The treating medical practitioner requested a chest x-ray which revealed a large left sided pleural effusion. The patient was subsequently transferred to a referral hospital (1 Military Hospital) in Pretoria, South Africa. Shortly after the patient arrived in the casualty department, he was in severe respiratory distress and active resuscitation had to be initiated. Despite full resuscitation efforts, the patient demised.

The deceased was referred for a medico-legal post mortem examination in terms of the Inquests Act 58 of 1959 (also in accordance with the Regulations Regarding the Rendering of Forensic Pathology Service R636) as a sudden and unexpected death.

A Lodox Statscan ${ }^{\circledR}$ was conducted prior to the commencement of the post mortem examination. Although the scan is conducted with the deceased in the supine position, the image depicted an enlarged cardiac shadow (possible cardiomegaly) as well as a pleural effusion on the left (Fig. 1). At autopsy, the external examination revealed the decedent to be of average physique and nutritional state (height of $175 \mathrm{~cm}$, weight of $68 \mathrm{~kg}$ and a BMI of 22.2). No abnormalities were evident during the external examination. Upon opening the body cavities, the left and right side of the pleural cavity contained $1200 \mathrm{ml}$ and $700 \mathrm{ml}$ blood stained fluid respectively. The heart was enlarged with a mass of $400 \mathrm{~g}$ (normal mass for body height $=217 \mathrm{~g}$ ) [1]. The left ventricular wall measured $1.2 \mathrm{~cm}$ in thickness (normal thickness for age $=1.14 \mathrm{~cm}$ ) [1]; however, marked right ventricular hypertrophy was present with the right ventricular wall measuring $0.8 \mathrm{~cm}$ in thickness (normal thickness for age $=$ $0.37 \mathrm{~cm})[1]$. The cusps of the heart valves appeared normal and the coronary arteries were patent. A large, fairly well encapsulated tumor mass was observed which filled the right 


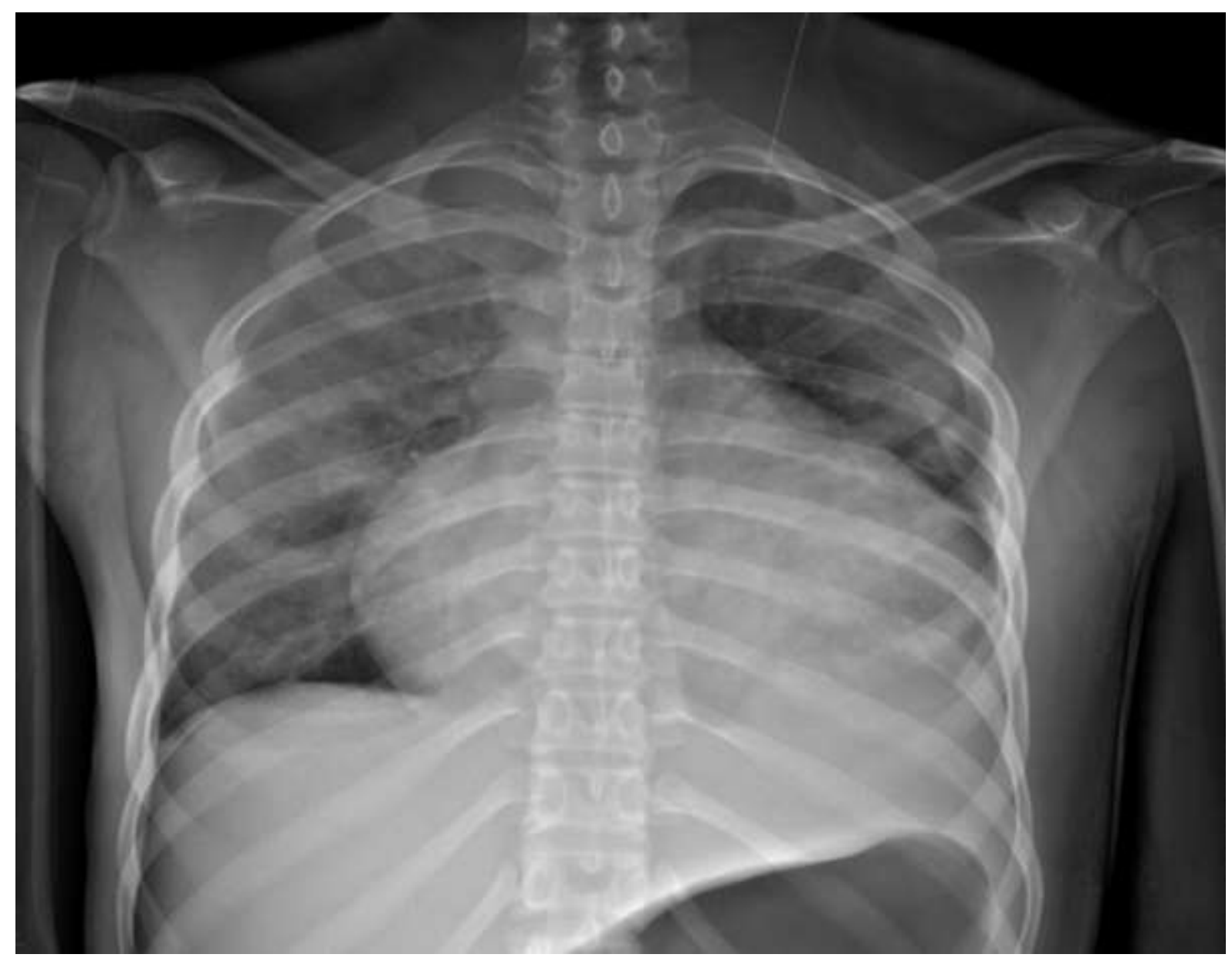

Figure 1: Lodox Statscan ${ }^{\circledR}$ showing possible cardiomegaly and left sided pleural effusion

atrium. The entire heart was retained and fixed in formalin for formal dissection. The tumor arose from the posterior aspect of the right auricle and was not attached to the interatrial septum (Fig. 2). Cross sectioning of the tumor revealed a predominantly friable texture of the tumor mass (Fig. 3 red arrow) with areas of necrosis and hemorrhage (Fig. 3 blue arrow) and focal firm, white, solid areas (Fig. 3 yellow arrow). The mass measured $7 \mathrm{~cm}$ in diameter and weighed 120 g (Fig. 3). 


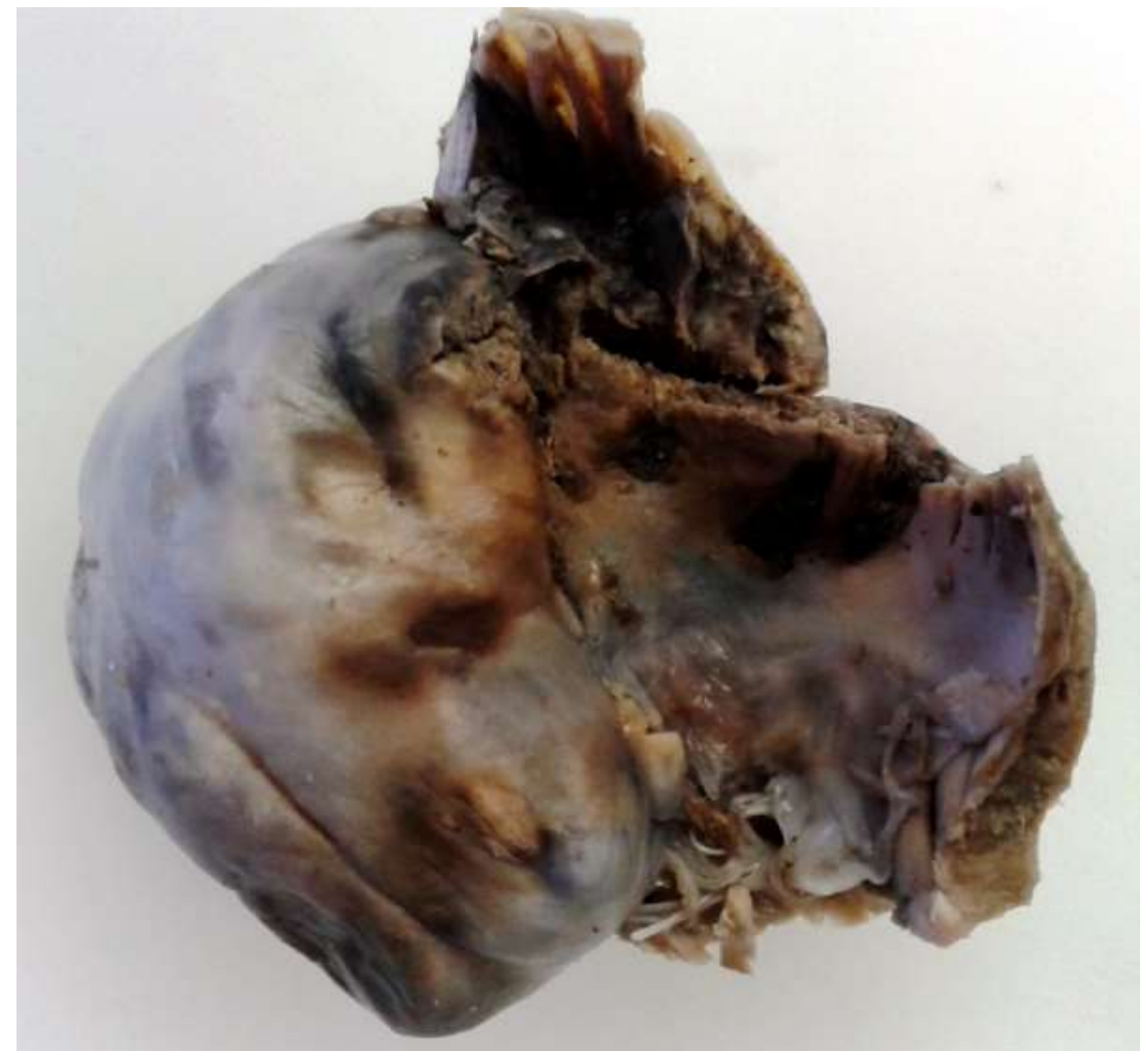

Figure 2: Large tumor mass originating from the right auricle (after formalin fixation) 


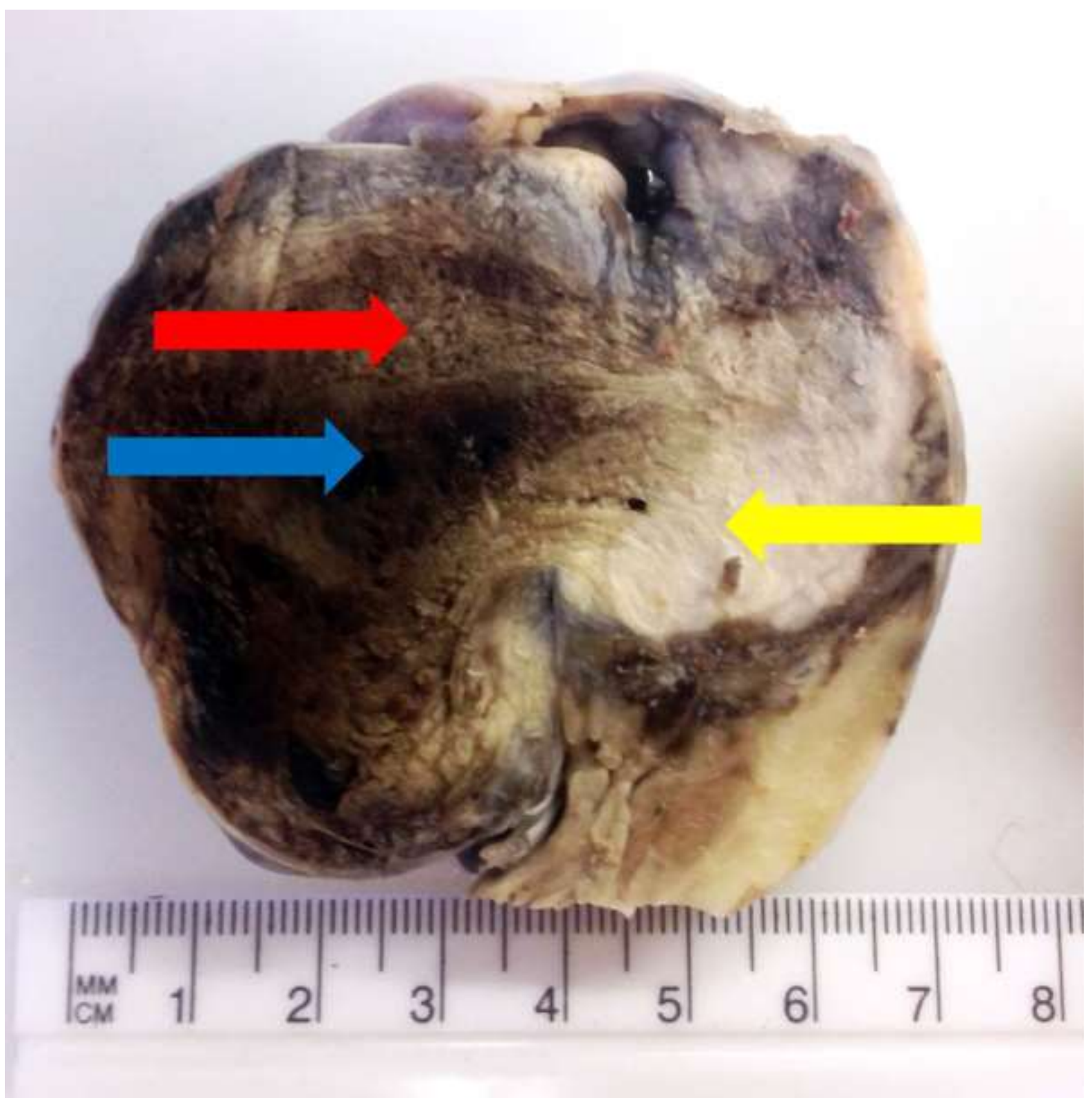

Figure 3: Cut surface of the tumor showing areas of necrosis and areas of a solid consistency

Histology of the tumor revealed cytologically atypical spindle with high cellular proliferation, arranged in fascicles. These cells had mildly atypical hyperchromatic nuclei with readily identified mitotic figures, along with indistinct palely eosinophilic cytoplasm. There was stromal hemorrhage (Fig. 4). Immunohistochemical staining was negative for actin, desmin, Myogenic Differentiation 1 (MyoD1), S100, chromogranin, ERG, Human Herpesvirus 8 


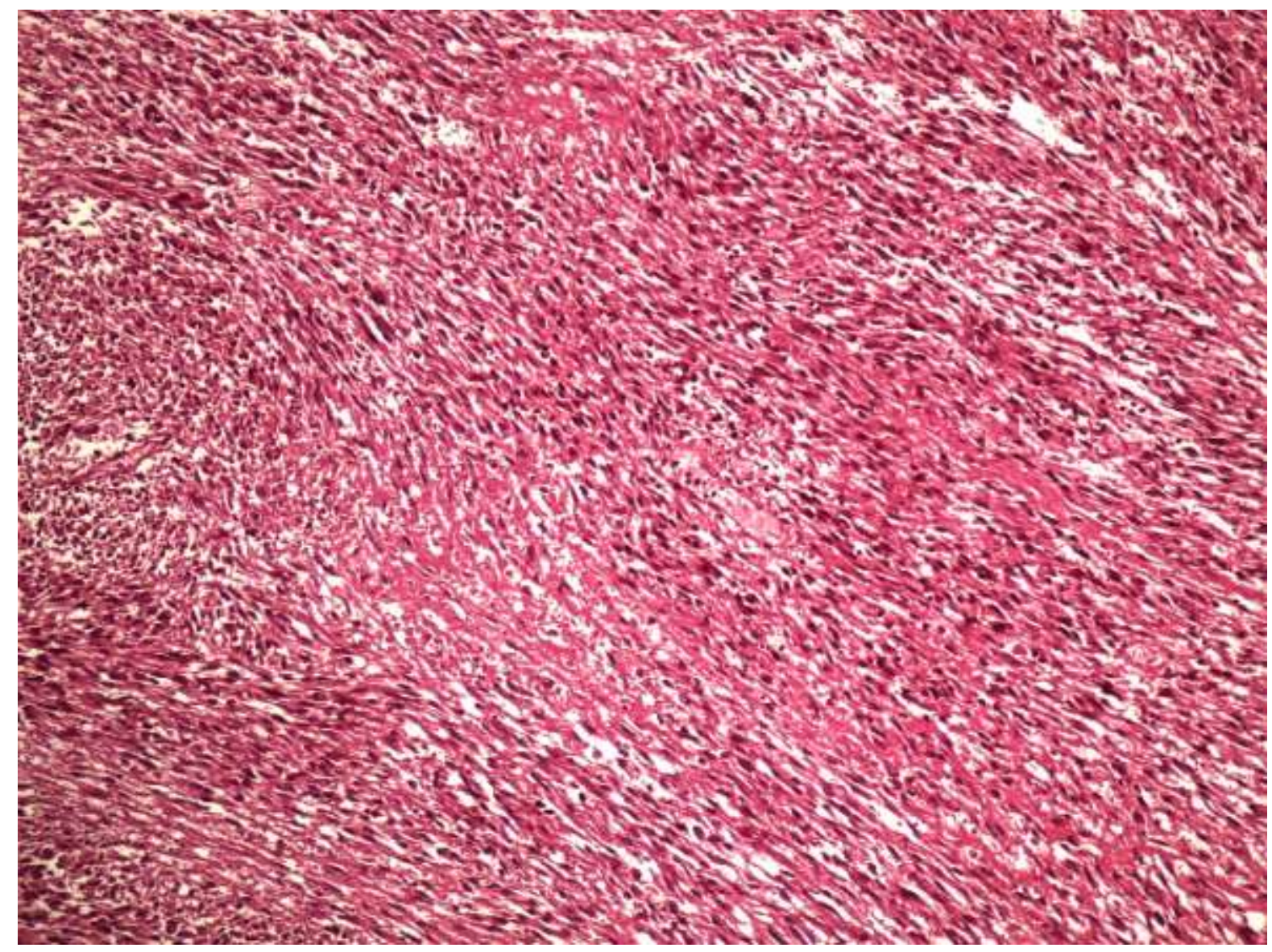

Figure 4: Hematoxylin and eosin (H\&E) section (magnification: X200) of the tumor showing a cardiac angiosarcoma with spindle cell morphology

(HHV-8) and CD34. The CD31 was diffusely positive (Fig. 5) and the Ki67 (proliferation marker) showed variable, focally significant reactivity. The diagnosis of a cardiac angiosarcoma with spindle cell morphology was made. 


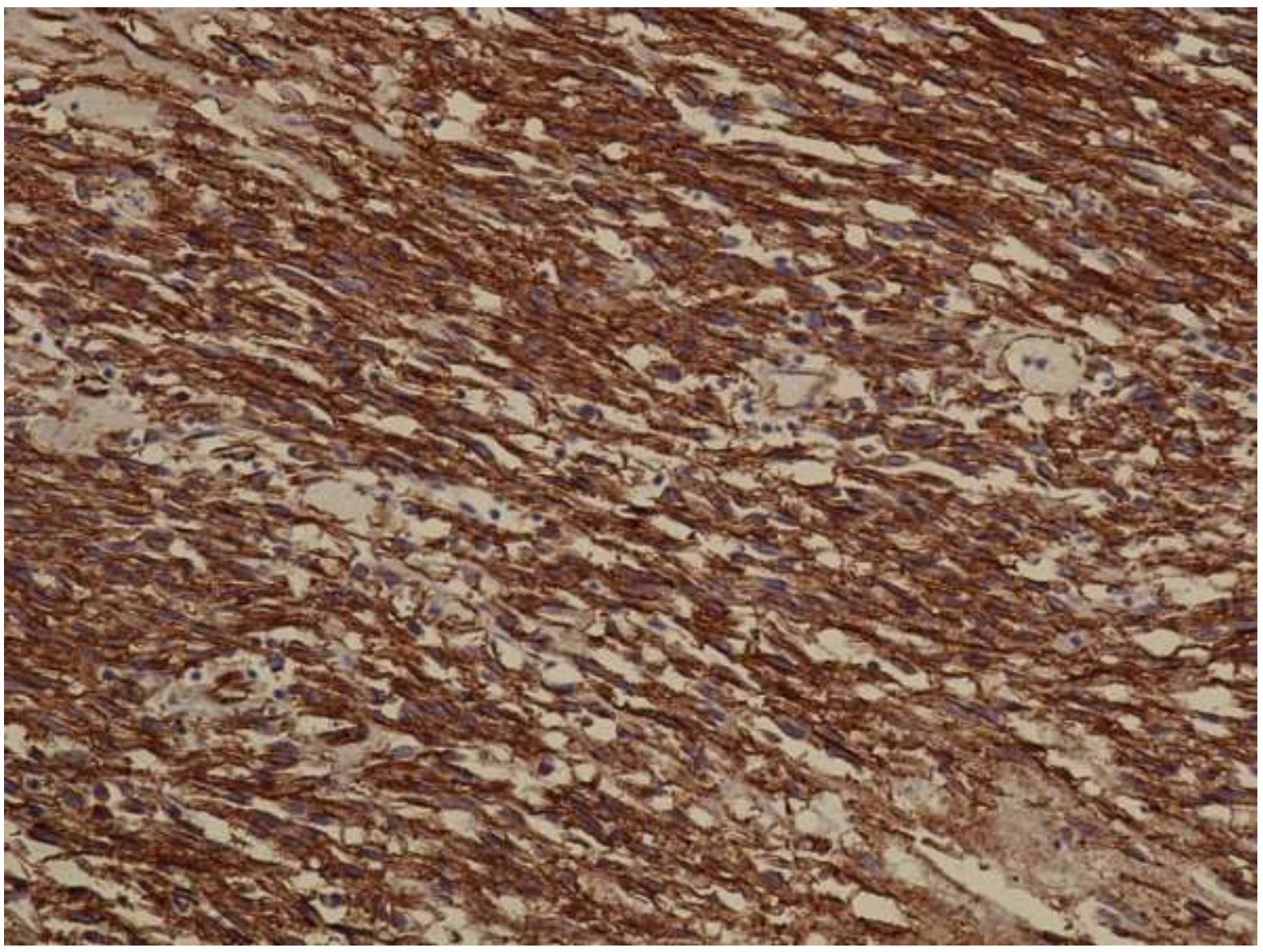

Figure 5: CD31 stain (magnification: $X 400$ ) confirming the endothelial origin of the

\section{tumor}

\section{Discussion}

Primary cardiac tumors are regarded as a rarity with the reported incidence at post mortem being between 0.0017 and $0.03 \%$ [2]. Furthermore, these tumors are also not frequently identified at forensic post mortem examinations [3]. Cina et al reported primary cardiac tumors in approximately $0.0025 \%$ of sudden cardiac death cases, the majority which will be investigated with a medico-legal post mortem examination $[4,5]$.

Cardiac tumors can broadly be classified into primary (benign and malignant) and secondary (metastatic) tumors of which the metastatic tumors more commonly encountered [6]. Benign tumors account for $75 \%$ of cases, the majority being myxomas followed by rhabdomyomas 
[2]. Malignant tumors constitute only $25 \%$ of cases; the vast majority of which are poorly differentiated sarcomas which cannot precisely be classified. In the event of possible histological/immunohistochemmical subtyping of sarcomas, angiosarcomas are mostly diagnosed [2]. Angiosarcomas are considered the most common tumor amongst the adult population and present typically in males between the $3^{\text {rd }}$ and $5^{\text {th }}$ decades of life [7]. Two macroscopic types of angiosarcomas are described: the first consists of tumor nodules in the epicardium or pericardium and the second is a large lesion usually in the right atrium [8].

Burke et al reported the incidence of angiosarcoma to be 1.7/100 000 cases [9]. Meng et al (China 1990-2000) evaluated 149 cases of primary cardiac tumors [10]. The latter authors indicated that $20.8 \%$ of primary tumors were malignant with $19.4 \%$ of these being angiosarcomas [10]. The study also indicated that nearly half of tumors which were present exclusively in the right side of the hart, were malignant [10]. In India, Kumar et al (19952010) reviewed surgical resected tumors and documented $92.4 \%$ as benign with only $7.6 \%$ malignant. Only 1 case of an angiosarcoma in a 59-year old female was described [6]. In contrast, Hoffmeier et al (Germany 1989 - 2012) reported a much higher rate of angiosarcomas in the heart (30\% of all malignancies) [11]. In Spain, Barreiro et al (19792012) indicated primary cardiac malignancies in $15.1 \%$ of cases with the majority being undifferentiated sarcomas (36.4\%) [12]. Only 2 cases of angiosarcoma were reported in the 32 year period [12].

Clinical symptoms of cardiac tumors include obstruction of the cardiac valve (direct obstruction by the large tumor mass), arrhythmias, tumor embolism as well as other systemic symptoms [10]. It has been documented that tumors which arise from the right side of the heart, specifically the posterior wall of the atrium with no connection to the interatrial 
septum, have a higher preponderance of being malignant $[7,10]$. Cine at al reported most angiosarcomas originate from the right side of the heart opposed to other cardiac malignancies [4]. Our case also represents a tumor arising from the posterior aspect of the right atrium with no connection to the interatrial septum. In our case, the size of the tumor most probably caused intermitted obstruction of the right ventricular outflow which resulted in the subsequent right ventricular hypertrophy.

Angiosarcomas are renowned to have a very poor prognosis [7]. Usually, treatment options are limited due to the aggressive nature of the tumor as well as the presence of metastases in the majority of cases when the initial diagnosis is made [7]. The association of sudden death, in especially younger individuals, is less commonly seen in primary angiosarcoma, with few case reports described. Tse et al reported the first case in 1971 followed by Walkely who reported a case in a 15 year old in 1987 [13, 14].

In 2002, Casha et al described the first case report of familial angiosarcoma in a 24 year old female whose father had died of the same tumor at the age of 31 years [15]. They also conducted cytogenetic studies and identified predominantly numeric abnormalities with gains on chromosome 1, 2, 7, 8 and 22 and monosomy of chromosome 19. The most significant finding was the presence of 2 copies of an unbalanced rearrangement seen in chromosome $8 p$ [15].

\section{Acknowledgements}

The authors would like to thank prof Christopher DM Fletcher for reviewing and confirming the histological diagnosis. 


\section{References}

1. Scholz DG, Kitzman DW, Hagen PT, Ilstrup DM, Edwards WD. Age-related changes in normal human hearts during the first 10 decades of life. Part I (Growth): A quantitative anatomic study of 200 specimens from subjects from birth to 19 years old. Mayo Clin Proc. 1988;63(2):126-36.

2. $\quad$ Silverman NA. Primary cardiac tumors. Ann Surg. 1980;191(2):127-38.

3. Beh P, Byard RW. Cardiac tumors and sudden death. Forensic Sci Med Pathol. 2014;10(2):269-71.

4. Cina SJ, Smialek JE, Burke AP, Virmani R, Hutchins GM. Primary cardiac tumors causing sudden death: a review of the literature. Am JForensic Med Pathol. 1996;17(4):27181 .

5. Ventura F, Landolfa MC, Leoncini A, Gentile R, Gaggero G, Bonsignore A, et al. Sudden death due to primary atrial neoplasms: report of two cases and review of literature. Forensic Sci Int. 2012;214(1-3):e30-3.

6. Kumar N, Agarwal S, Ahuja A, Das P, Airon B, Ray R. Spectrum of cardiac tumors excluding myxoma: Experience of a tertiary center with review of the literature. Pathol Res Pract. 2011;207(12):769-74.

7. Kurian KC, Weisshaar D, Parekh H, Berry GJ, Reitz B. Primary cardiac angiosarcoma: case report and review of the literature. Cardiovasc Pathol. 2006;15(2):110-2. 8. Maraj S, Pressman GS, Figueredo VM. Primary cardiac tumors. Int J Cardiol. 2009;133(2):152-6.

9. Burke AP, Cowan D, Virmani R. Primary sarcomas of the heart. Cancer. 1992;69(2):387-95.

10. Meng Q, Lai H, Lima J, Tong W, Qian Y, Lai S. Echocardiographic and pathologic characteristics of primary cardiac tumors: a study of 149 cases. Int J Cardiol. 2002;84(1):6975 .

11. Hoffmeier A, Sindermann JR, Scheld HH, Martens S. Cardiac tumors--diagnosis and surgical treatment. Dtsch Arztebl Int. 2014;111(12):205-11.

12. Barreiro M, Renilla A, Jimenez JM, Martin M, Al Musa T, Garcia L, et al. Primary cardiac tumors: 32 years of experience from a Spanish tertiary surgical center. Cardiovasc Pathol. 2013;22(6):424-7.

13. Tse RL, Frank MN. Angiosarcoma of the heart. First reported case in an adolescent. Angiology. 1971;22(3):147-52.

14. Wakely PE, Jr. Angiosarcoma of the heart in an adolescent. A light and electron microscopic and immunohistochemical study. Arch Pathol Lab Med. 1987;111(5):472-5.

15. Casha AR, Davidson LA, Roberts P, Nair RU. Familial angiosarcoma of the heart. J Thorac Cardiovasc Surg. 2002;124(2):392-4. 